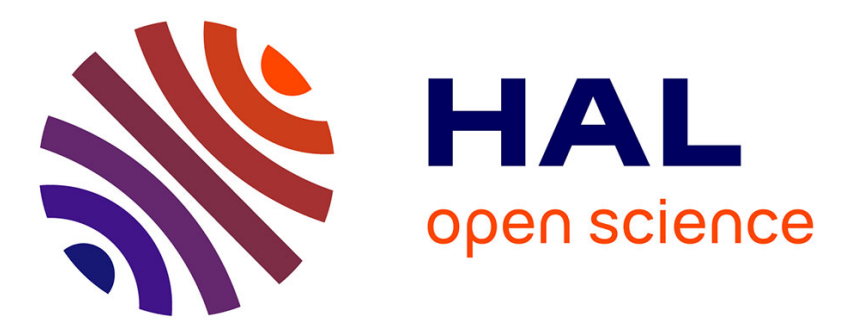

\title{
Stability and electronic spectra of copper(II) halides in butan-1-ol and the effects of R-OH type solvents on these properties.
}

\author{
E. Bentouhami, Mustayeen A. Khan, J. Meullemeestre, F. Vierling
}

\section{- To cite this version:}

E. Bentouhami, Mustayeen A. Khan, J. Meullemeestre, F. Vierling. Stability and electronic spectra of copper(II) halides in butan-1-ol and the effects of R-OH type solvents on these properties.. Polyhedron, 1992, 11 (17), pp.2179-2182. 10.1016/S0277-5387(00)83693-1 . hal-03171275

HAL Id: hal-03171275

https://univ-angers.hal.science/hal-03171275

Submitted on 20 Mar 2021

HAL is a multi-disciplinary open access archive for the deposit and dissemination of scientific research documents, whether they are published or not. The documents may come from teaching and research institutions in France or abroad, or from public or private research centers.
L'archive ouverte pluridisciplinaire HAL, est destinée au dépôt et à la diffusion de documents scientifiques de niveau recherche, publiés ou non, émanant des établissements d'enseignement et de recherche français ou étrangers, des laboratoires publics ou privés. 


\title{
STABILITY AND ELECTRONIC SPECTRA OF COPPER(II) HALIDES IN BUTAN-1-OL AND THE EFFECTS OF $\mathbb{R}-\mathrm{OH}$ TYPE SOLVENTS ON THESE PROPERTIES
}

\author{
E. BENTOUHAMI,* M. A. KHAN, $\dagger$ J. MEULLEMEESTRE and F. VIERLING \\ Laboratoire de Chimie-Physique, EHICS, URA No. 405 CNRS, Université Louis Pasteur, \\ 67000 Strasbourg, France
}

(Received 18 March 1992; accepted 12 May 1992)

\begin{abstract}
Copper(II) halide complexes were studied in butan-1-ol at $25^{\circ} \mathrm{C}$ and at constant ionic strength. Formation constants and electronic spectra of all the complexes present in the solution were calculated. The apparent stability of these complexes increases with the number of carbon atoms in the alcohol: the logarithm of the overall stability constant, $\beta_{j}$, is a linear function of their molecular weights. A regular decrease of the stability with the permittivity of the pure solvents is observed. This result is correlated with the increasing dissociating power of the solvents which promotes better hydrogen bonding and hinders the substitution of the solvent molecule by the ligand in the inner coordination sphere of the metal. There is hardly any $\mathrm{R}-\mathrm{OH}$-type solvent effect on the electronic spectra of the individual species. Tetrabromocuprate is always present in $D_{2 d}$ symmetry, whereas the configuration of tetrachlorocuprate is $D_{4 h}$ in methanol and $D_{2 d}$ in the higher alcohols.
\end{abstract}

We have already reported the results of studies of copper(II) halide complexes in methanol, ${ }^{1}$ ethanol ${ }^{2}$ and propan-2-ol. ${ }^{3}$ This paper deals with the results of copper(II) halide complexes in butan-1-ol and the correlation of their properties such as stability, electronic spectra and structure in the alcohols.

$$
\mathrm{Cu}^{2+}+j \mathrm{X}^{-} \rightleftarrows \mathrm{CuX}_{j}^{(j-2)-} \quad(\mathrm{X}=\mathrm{Cl}, \mathrm{Br})
$$

The successive equilibria were studied in butanol at $25^{\circ} \mathrm{C}$ and at constant ionic strength and the overall stability constants, $\beta_{j}$, of the complexes present in solution were calculated. A detailed bibliography on the subject has already been given in our earlier publications. ${ }^{1,2}$ We further recall that transferring the ionic strength concept to this non-aqueous medium with the assumption of the activity coefficients' stabilization, the interpretation of the superposed equilibria in non-aqueous solutions is possible: it leads to "apparent stability constants"

* Institut de Chimie, Université de Sétif, 19000 Sétif, Algérie.

† Present address: Faculté de Pharmacie, Université d'Angers, 49100 Angers, France.

\$ Author to whom correspondence should be addressed. which can be used as "thermodynamic parameters". ${ }^{3}$

\section{EXPERIMENTAL}

Butan-1-ol, Prolabo p.a., was used as a solvent. Stock solutions of lithium perchlorate, copper(II) perchlorate, lithium chloride and lithium bromide (all Fluka p.a.) were prepared by dissolving calculated quantities in the solvent. Exact concentrations were determined gravimetrically, except the copper solution which was titrated against EDTA using murexide as an indicator. ${ }^{4}$

Ligand concentrations were kept higher than that of the metal and the ionic strength was kept constant at $1 \mathrm{~mol} \mathrm{dm}^{-3}$, as in our earlier work. Experimental conditions were identical to those maintained in other alcohols.

\section{RESULTS AND DISCUSSION}

The experimental spectra of the copper(II) chlorides and bromides are represented in Figs 1 and 2, respectively. For the chloride solutions there is an intense absorption at $285 \mathrm{~nm}$ in the UV, another large band in the visible at $395 \mathrm{~nm}$ and in the IR 
region a maximum at $1050 \mathrm{~nm}$ for the analytical ligand concentration $C=1 \mathrm{~mol} \mathrm{dm}{ }^{-3}$. The presence of four isosbestic points is to be observed at 270, 310, 360 and $920 \mathrm{~nm}$.

The absorption variations of the bromide solutions are, as usual, more complicated than the chlorides. In short, there is an absorption maximum at $305 \mathrm{~nm}$ which, at higher ligand concentrations, splits into two bands at 280 and $340 \mathrm{~nm}$. There is another absorption at $580 \mathrm{~nm}$ which also splits into a maximum at 525 , along with a residual absorption at about $620 \mathrm{~nm}$. Finally, in the IR region, at higher ligand concentrations, there are two absorption maxima at 950 and $1110 \mathrm{~nm}$. In this system there are five isosbestic points, viz. 295, 320, 400, 472 and $1040 \mathrm{~nm}$.

For a numerical analysis, the first step in these types of problems is to determine the number of absorbing species present in the solution. This was determined by the matrix rank treatment method of Hugus and El Awady ${ }^{5}$ on a set of experimental data of $N \times L$ absorptions, where $L=$ the number of wavelengths and $N=$ the number of solutions. In all 819 experimental values in the chloride system and 1101 in the bromide system, i.e. 1920 measurements, were computed. The mathematical expressions used in calculations have been explained in our earlier publications. ${ }^{6,7}$ As was the case with the first three alcohols, a minimum of three complexes were indicated for the chlorides as well as the bromides. We therefore tested theoretical models $[1,2,3]$ and $[1,2,3,4]$, that is for three and four successive mononuclear complexes.

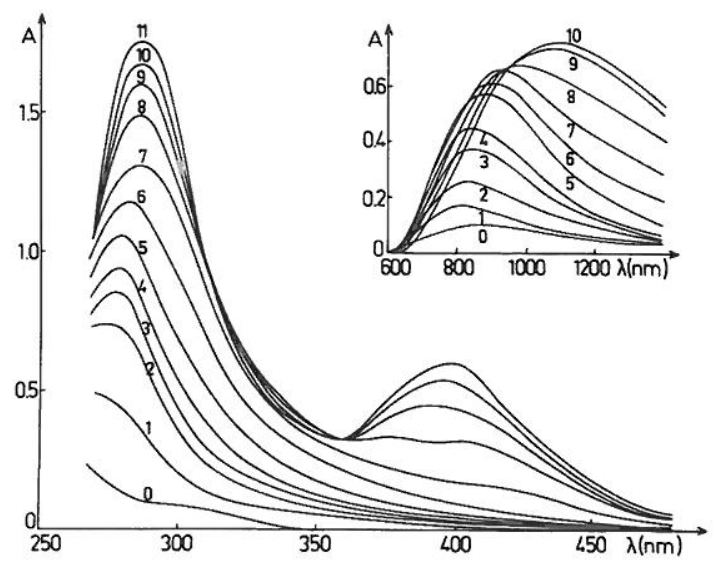

Fig. 1. Absorption spectra of copper(II)- $\mathrm{Li}^{+}\left(\mathrm{Cl}^{-}\right.$, $\left.\mathrm{ClO}_{4}{ }^{-}\right) 1 \mathrm{M}$ solutions in anhydrous butan-1-ol. UV-vis : $\left[\mathrm{Cu}^{\mathrm{II}}\right]=3 \times 10^{-4} \mathrm{~mol} \mathrm{dm}{ }^{-3} ; l_{\text {cuve }}=1 \mathrm{~cm} \mathrm{spectrum} /\left[\mathrm{Cl}^{-}\right]$ $\left(\mathrm{mol} \mathrm{dm}^{-3}\right): 0 / 0,1 / 0.0005,2 / 0.001,3 / 0.002,4 / 0.004$, $5 / 0.008,6 / 0.02,7 / 0.06,8 / 0.2,9 / 0.4,10 / 0.6,11 / 1.0$. NearIR: $\left[\mathrm{Cu}^{\mathrm{II}}\right]=3 \times 10^{-3} \mathrm{~mol} \mathrm{dm}^{-3} ; l_{\text {cuve }}=2 \mathrm{~cm}$ spectrum/ $\left[\mathrm{Cl}^{-}\right]\left(\mathrm{mol} \mathrm{dm}{ }^{-3}\right): 0 / 0,1 / 0.0005,2 / 0.002,3 / 0.004$ 4/0.006, 5/0.02, 6/0.04, 7/0.08, 8/0.2, 9/0.6, 10/1.0.

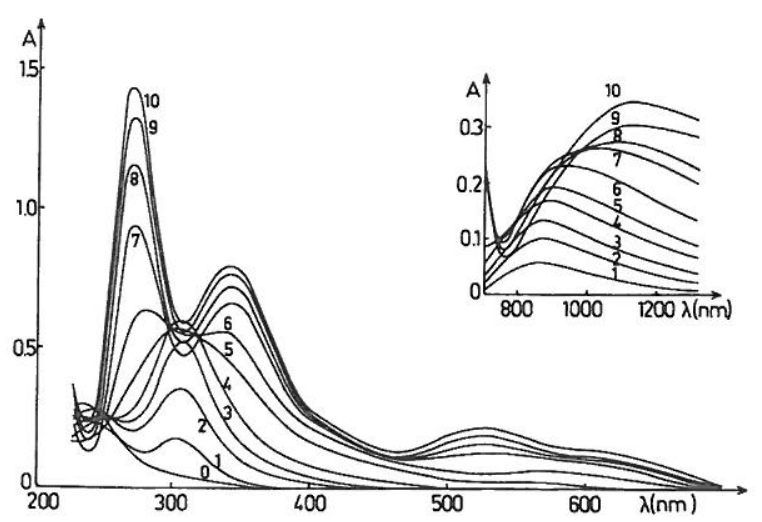

Fig. 2. Absorption spectra of copper(II)- $\mathrm{Li}^{+}\left(\mathrm{Br}^{-}\right.$, $\left.\mathrm{ClO}_{4}{ }^{-}\right) 1 \mathrm{M}$ solutions in anhydrous butan-1-ol. UV-vis : $\left[\mathrm{Cu}^{\mathrm{II}}\right]=1 \times 10^{-3} \mathrm{~mol} \mathrm{dm}{ }^{-3} ; l_{\text {cuve }}=0.2 \mathrm{~cm}$ spectrum $/$ $\left[\mathrm{Br}^{-}\right]\left(\mathrm{mol} \mathrm{dm}^{-3}\right): 0 / 0,1 / 0.001,2 / 0.002,3 / 0.004,4 / 0.01$, 5/0.04, 6/0.1, 7/0.4, 8/0.6, 9/0.8, 10/1.0. Near-IR: $\left[\mathrm{Cu}^{\mathrm{II}}\right]=1 \times 10^{-3} \mathrm{~mol} \mathrm{dm}{ }^{-3} ; l_{\text {cuve }}=2 \mathrm{~cm}$ spectrum $/\left[\mathrm{Br}^{-}\right]$ $\left(\mathrm{mol} \mathrm{dm}^{-3}\right): 1 / 0.001,2 / 0.003,3 / 0.006,4 / 0.01,5 / 0.02$, $6 / 0.04,7 / 0.1,8 / 0.4,9 / 0.6,10 / 1.0$.

The results in Table 1 show that whatever the system, the total standard deviation, $\sigma_{t}$, is lower for the model with four complexes and therefore, mathematically, the presence of four complexes is indicated. However, we already pointed out in one of our earlier publications ${ }^{1}$ that the mathematical criterion in itself is not sufficient and should be sustained by spectroscopic arguments. In the case of the chloride system, for example, the observed coordinates of the isosbestic points, viz. $270 \mathrm{~nm}$ (3670 $\mathrm{dm}^{3} \mathrm{~mol} \mathrm{~cm}^{-1}$ ), 310 (3240), 360 (1120), 950 (112), are in excellent agreement with those calculated for the $[1,2,3,4]$ model : $270 \mathrm{~nm}\left(3600 \mathrm{dm}^{3}\right.$ $\mathrm{mol}^{-1} \mathrm{~cm}^{-1}$ ), 380 (3420), 360 (1130), 950 (112). The

Table 1. Overall stability constants, $\beta_{j}$, of chloro- and bromo-complexes for the $[1,2,3]$ and $[1,2,3,4]$ models

\begin{tabular}{ccc}
$\mathrm{CuCl}^{+}$ & $5.0 \times 10^{7}$ & $4.1 \times 10^{7}$ \\
$\mathrm{CuCl}_{2}$ & $7.2 \times 10^{9}$ & $1.2 \times 10^{11}$ \\
$\mathrm{CuCl}_{3}{ }^{-}$ & $3.7 \times 10^{10}$ & $5.7 \times 10^{12}$ \\
$\mathrm{CuCl}_{4}{ }^{2-}$ & - & $2.3 \times 10^{13}$ \\
$\sigma_{\mathrm{UV}-\text { vis }}$ & 0.0722 & 0.0498 \\
$\sigma_{\mathrm{IR}}$ & 0.1804 & 0.1706 \\
$\sigma_{\mathrm{t}}$ & 0.1335 & 0.1215 \\
$\mathrm{CuBr}^{+}$ & $2.0 \times 10^{8}$ & $2.5 \times 10^{9}$ \\
$\mathrm{CuBr}_{2}$ & $1.7 \times 10^{10}$ & $1.3 \times 10^{12}$ \\
$\mathrm{CuBr}^{-}$ & $6.5 \times 10^{10}$ & $3.4 \times 10^{13}$ \\
$\mathrm{CuBr}_{4}{ }^{2-}$ & - & $1.2 \times 10^{14}$ \\
$\sigma_{\mathrm{UV}-\text { vis }}$ & 0.1335 & 0.0925 \\
$\sigma_{\mathrm{IR}}$ & 0.1522 & 0.1409 \\
$\sigma_{\mathrm{t}}$ & 0.1386 & 0.1073 \\
\hline
\end{tabular}




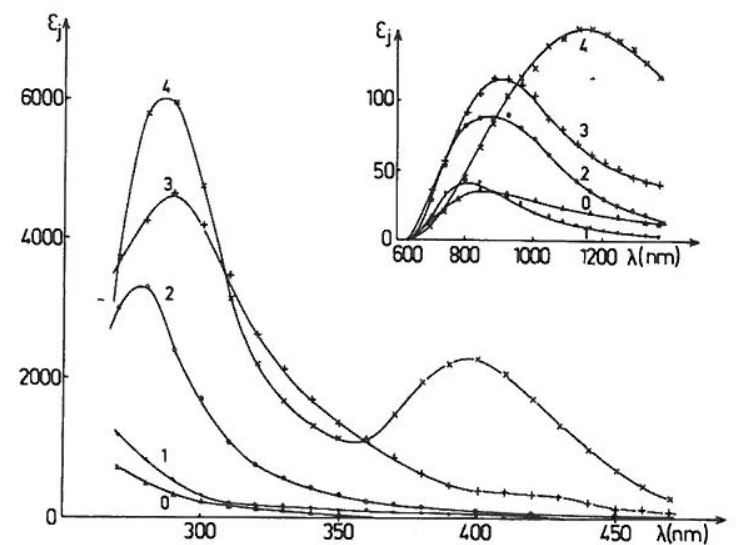

Fig. 3. Calculated electronic spectra of copper(II)-chlorocomplexes in butan-1-ol for the model $[1,2,3,4]$.

isosbestic points pertain to the equilibrium between the trichloro and tetrachloro complexes.

The electronic spectra of individual species are shown in Figs 3 and 4 and the characteristic absorption bands are summarized in Table 2 .

The tetrahalogenocuprates have their $d-d$ transition bands at 1120 and $1200 \mathrm{~nm}$ and therefore have configurations of $D_{2 d}$ symmetry. We may recall here that in tetra-coordinated copper complexes $d-d$ transitions at $1100 \mathrm{~nm}$ and above are due to structures of $D_{2 d}$ symmetry.

With the results of copper(II) halide complexes in butanol, we are now in a position to see clearly the different aspects of solvent effects on different properties of these complexes.

Table 3 gives the logarithms of overall stability constants, $\log \beta_{j}$, in the four alcohols and confirms our earlier assumption ${ }^{3}$ that in a given solvent the bromides are generally more stable than the chlorides. Furthermore, it is seen that the stability of a given complex increases from methanol to butanol-the plot of $\log \beta_{j}$ against molecular weights of

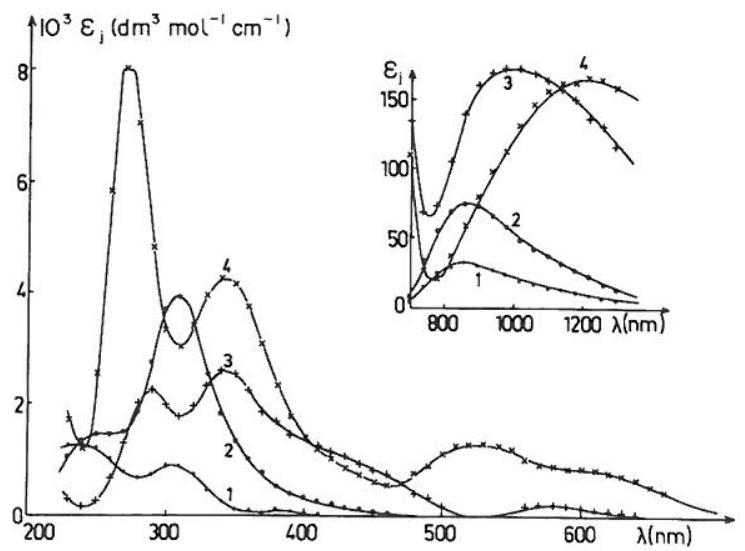

Fig. 4. Calculated electronic spectra of copper(II)bromo-complexes in butan-1-ol for the model [1, 2, 3, 4].
Table 2. Characteristic absorption bands of all species present in the solution ( $\mathrm{sh}=$ shoulder peak)

\begin{tabular}{ccc}
\hline & $\begin{array}{c}\text { Chloro-complexes } \\
\lambda_{\text {max }}(\mathrm{nm}) ; \varepsilon_{\max } \\
\left(\mathrm{dm}^{3} \mathrm{~mol}^{-1} \mathrm{~cm}^{-1}\right)\end{array}$ & $\begin{array}{c}\text { Bromo-complexes } \\
\lambda_{\max }(\mathrm{nm}) ; \varepsilon_{\text {max }} \\
\left(\mathrm{dm}^{3} \mathrm{~mol}^{-1} \mathrm{~cm}^{-1}\right)\end{array}$ \\
\hline $\mathrm{Cu}^{2+}$ & 260 & $230(1530)$ \\
$\mathrm{CuX}^{+}$ & $820(30)$ & $820(32)$ \\
& $265(\approx 1200)$ & $240(1300)$ \\
$\mathrm{CuX}_{2}$ & $810(48)$ & $306(920)$ \\
& $280(3300)$ & $245 \mathrm{sh}$ \\
$\mathrm{CuX}_{3}{ }^{-}$ & $850(93)$ & $310(3925)$ \\
& $270 \mathrm{sh}$ & $860(75)$ \\
& $290(4630)$ & $290(2450)$ \\
& $420 \mathrm{sh}$ & $460 \mathrm{sh}$ \\
& $910(114)$ & $980(172)$ \\
$\mathrm{CuX}_{4}{ }^{2-}$ & $290(5950)$ & $270(8020)$ \\
& $395(2300)$ & $340(4220)$ \\
& $1120(160)$ & $530(1290)$ \\
& $600(850)$ \\
& & $1200(167)$ \\
& &
\end{tabular}

the alcohols is an increasing linear function [Fig. 5(a) and (b)]. This evolution is roughly true for the bromides but is very well respected in the chloride system. Theoretically, it is a very interesting relation which enables the prediction of the values of stability constants of copper(II) halide complexes in other alcohols, for example, pentanol, a very significant solvent, without undertaking (a priori) an experimental study. As far as we know this is the

Table 3. Logarithm of stability constants of chloro- and bromo-complexes of copper in different alcohols

\begin{tabular}{ccccc}
\hline $\begin{array}{c}\text { Solvent } \\
\text { permittivity, } \varepsilon_{\mathrm{r}}\end{array}$ & $\begin{array}{c}\text { MeOH } \\
\text { Molecular weight, } \\
\text { Mol.wt }\end{array}$ & $\begin{array}{c}\text { EtOH } \\
\text { PrOH-2 }\end{array}$ & $\begin{array}{c}\text { BuOH-1 } \\
19.5\end{array}$ & 17 \\
\hline Chloro-complexes & 32 & 46 & 60 & 74 \\
$\log \beta_{1}$ & 2.5 & 3.3 & 5.7 & 7.6 \\
$\log \beta_{2}$ & 4.2 & 6.0 & 8.6 & 11.1 \\
$\log \beta_{3}$ & 5.4 & 7.8 & 10.2 & 12.8 \\
$\log \beta_{4}$ & 5.7 & 8.3 & 10.6 & 13.4 \\
Bromo- $\operatorname{complexes}$ & & & & \\
$\log \beta_{1}$ & 3.7 & 5.0 & 6.1 & 9.4 \\
$\log \beta_{2}$ & 5.6 & 7.8 & 8.4 & 12.1 \\
$\log \beta_{3}$ & 6.3 & 9.2 & 10.2 & 13.5 \\
$\log \beta_{4}$ & 6.3 & 10.3 & 10.7 & 14.1 \\
\hline
\end{tabular}



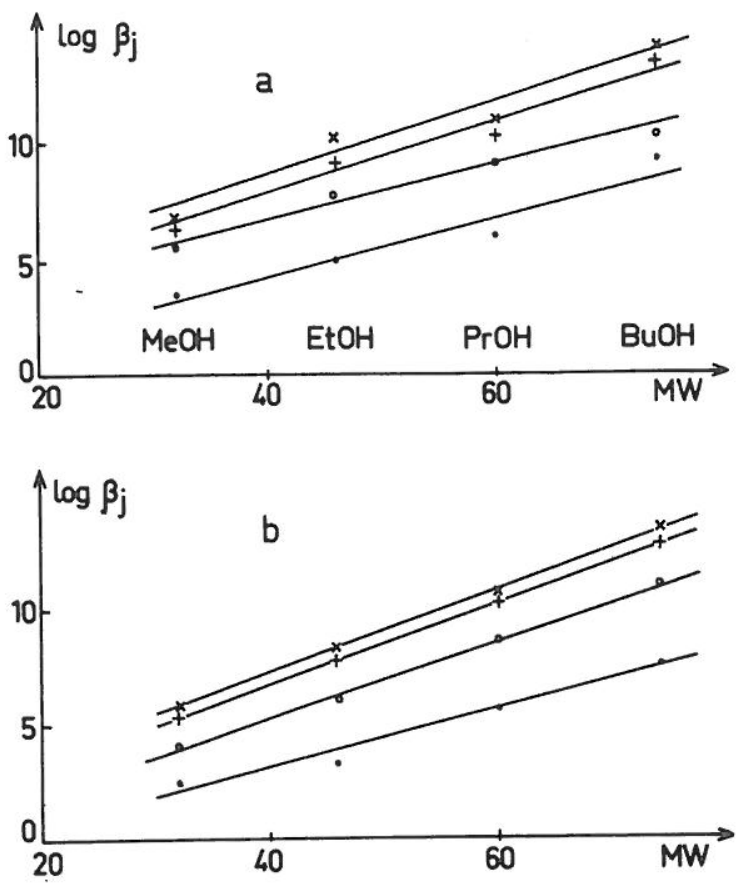

Fig. 5. Variation of the logarithm of the overall stability constants of the copper(II)-halogen-complexes with the molecular weight of the $\mathrm{R}-\mathrm{OH}$ type solvents : (a) bromides and (b) chlorides.

first time that such a relation has been established in a specific type of solvent.

We may point out here that values of $\log \beta_{j}$ were plotted against molecular weights of the alcoholsa property which remains constant and unchanged. When dielectric constants of solvents are used care has to be taken to distinguish between the static dielectric constant, which is the permittivity of the pure solvent, and the variable dielectric constant, which changes with respect to the concentration of species in the solvent. ${ }^{8}$ Nevertheless, a regular decrease of the stability of the complexes is observed with the dielectric constants of the solvents: the variation is close to linearity with dielectric constant values higher than 20 .

The principal absorption bands of the complexes in butanol have been tabulated in Table 2. A comparison with those in other alcohols has shown no significant solvent effects on the characteristic absorption maxima in the UV and visible regions. All these absorptions in all the four alcohols can be located at $\pm 5 \mathrm{~nm}$.

The structures of the tetra-coordinated complexes in the four alcohols can be compared to see the solvent effect on this property. The tetra- chlorocuprate is known to exist under $D_{4 h}$ or $D_{2 d}$ configurations : the main difference between the two structures is that the ion of symmetry $D_{4 h}$ presents $d-d$ transitions below $1100 \mathrm{~nm}$, whereas the $D_{2 d}$ structure presents these bands at $1100 \mathrm{~nm}$ and above. This transition is at $1000 \mathrm{~nm}$ in methanol and at $c a 1100 \mathrm{~nm}$ in the other three alcohols. Therefore, $\mathrm{CuCl}_{4}{ }^{2-}$ has a $D_{4 h}$ symmetry in methanol and a $D_{2 d}$ symmetry in the other three alcohols.

Demuynck et al., ${ }^{9}$ using LCAO-MO-SCF $a b$ initio calculations in a thereotical study of bonding in $\mathrm{CuCl}_{4}{ }^{2-}$, showed that the configuration $T_{d}$ is more stable, $c a 72 \mathrm{~kJ} \mathrm{~mol}^{-1}$, than the configuration $D_{4 h}$ and that the configuration $D_{2 d}$ is still more stable, by about $8 \mathrm{~kJ} \mathrm{~mol}^{-1}$. The difference in energy calculated between these three configurations is, however, sufficiently low and the geometry of the molecule can easily be influenced by its surroundings.

In the solid state, $\mathrm{CuBr}_{4}{ }^{2-}$ has never been observed in $D_{4 h}$ symmetry, under normal conditions of temperature and pressure. Wang and Drickamer ${ }^{10}$ have reported this structure but at pressures higher than $60 \mathrm{kbar}\left(6.10^{9} \mathrm{~Pa}\right)$. The tetrabromocuprate has, in all the alcohols, its $d-d$ transitions at about 1100 and above and consequently exists exclusively in $D_{2 d}$ symmetry in solution.

\section{REFERENCES}

1. M. A. Khan, J. Meullemeestre, M. J. Schwing and F. Vierling, Inorg. Chem. 1989, 28, 3306.

2. S. Chafaa, T. Douadi, M. A. Khan, J. Meullemeestre, M. J. Schwing and F. Vierling, New J. Chem. 1991, $15,39$.

3. S. Dali, F. Benghanem, M. A. Khan, J. Meullemeestre and F. Vierling, Polyhedron 1991, 10, 2529.

4. H. A. Flaschka, E.D.T.A. Titrations, p. 82. Pergamon Press, Oxford (1964).

5. Z. Z. Hugus and A. A. El Awady, J. Phys. Chem. 1971, 75, 2957.

6. M. Elleb, J. Meullemeestre, M. J. Schwing and F. Vierling, Inorg. Chem. 1980, 19, 2699.

7. F. Vierling, M. J. Schwing and J. Meullemeestre, Spectra 2000 1982, 79, 25.

8. G. Kortum, Treatise on Electrochemistry: Dielectric Constants and the Dissociating Power of Liquids, pp. 135-144. Elsevier Publishing Co., Amsterdam (1985).

9. J. Demuynck, A. Veillard and U. Wahlgren, J. Am. Chem. Soc. 1973, 95, 5563.

10. P. J. Wang and H. G. Drickamer, J. Chem. Phys. 1973, 59, 559 . 